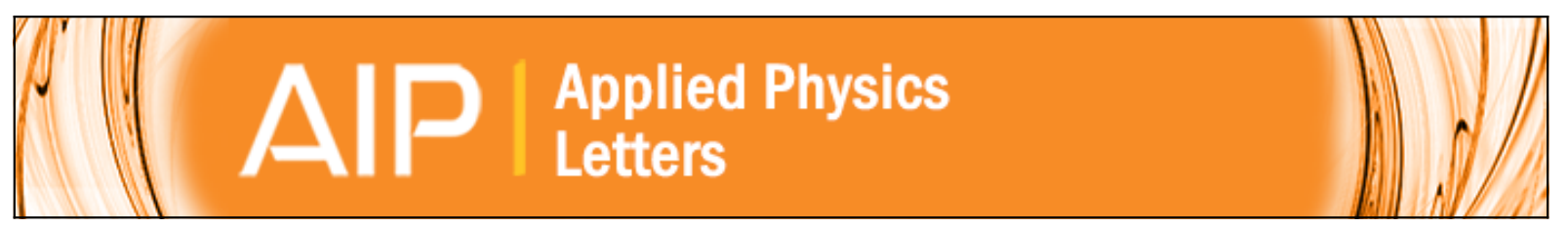

Ultrathin oxidized Ti to increase stability and smoothness of Al doped $\mathrm{ZnO}$ transparent conductors for high efficiency indium-free polymer solar cells

N. Formica, D. S. Ghosh, A. Martinez-Otero, T. L. Chen, Jordi Martorell, and V. Pruneri

Citation: Applied Physics Letters 103, 183304 (2013); doi: 10.1063/1.4827877

View online: http://dx.doi.org/10.1063/1.4827877

View Table of Contents: http://scitation.aip.org/content/aip/journal/apl/103/18?ver=pdfcov

Published by the AIP Publishing 


\title{
Ultrathin oxidized Ti to increase stability and smoothness of Al doped ZnO transparent conductors for high efficiency indium-free polymer solar cells
}

\author{
N. Formica, ${ }^{1, a)}$ D. S. Ghosh, ${ }^{1, b)}$ A. Martinez-Otero, ${ }^{1}$ T. L. Chen, ${ }^{1}$ Jordi Martorell, ${ }^{1,2,3}$ \\ and V. Pruneri ${ }^{1,2}$ \\ ${ }^{1}$ ICFO-Institut de Ciències Fotòniques, Mediterranean Technology Park, 08860 Castelldefels, \\ Barcelona, Spain \\ ${ }^{2}$ ICREA - Institució Catalana de Recerca i Estudis Avançats, 08010 Barcelona, Spain \\ ${ }^{3}$ Departament de Física i Enginyeria Nuclear, Universitat Politècnica de Catalunya, Terrassa, Spain
}

(Received 1 August 2013; accepted 15 October 2013; published online 1 November 2013)

\begin{abstract}
We propose a transparent electrode consisting of an aluminum doped zinc oxide (AZO) layer capped with an ultrathin oxidized Ti film for indium-free bulk-heterojunction polymer solar cells (PSCs). The oxidized Ti increases the chemical, environmental, stability and the surface smoothness of AZO while still maintaining its electrical and optical properties. The application potential of the proposed transparent electrode is demonstrated in an inverted PSC, which shows an efficiency of $6.3 \%$, very close to the value (7\%) obtained in a similar structure using indium tin oxide. This efficiency is the highest reported to date for PSCs incorporating AZO electrodes. (c) 2013 AIP Publishing LLC. [http://dx.doi.org/10.1063/1.4827877]
\end{abstract}

Organic photovoltaics technology is a quickly expanding research field due to its distinct advantages over its inorganic counterpart. These include the large variety of colors, good transparency, versatile materials synthesis, light weight, freedom of product design, and low-cost mass production by using roll-to-roll technique on flexile substrates. ${ }^{1-4}$ Bulk hetero-junction (BHJ) polymer solar cells (PSCs) have become one of the most successful device structure developed to date, with power-conversion efficiencies (PCE) now exceeding 7\%. ${ }^{5-7} \mathrm{BHJ}$ devices with a direct architecture or a more stable inverted structure usually employ indium tin oxide (ITO) as bottom transparent electrode since it provides the best performance in terms of electro-optical efficiency and stability. However, its use represents an industrial bottleneck since the cost of its main element, indium, is steadily increasing due to limited supply and heavy demand. Therefore, the development of ITO-free transparent electrodes and PSCs is crucial.

Possible replacements of ITO include other transparent conducting oxides (TCOs), conducting polymers, carbon nanotube films, graphene, and silver nanowires. ${ }^{8-12}$ Impurity doped polycrystalline $\mathrm{ZnO}$ materials such as $\mathrm{Al}-$ or $\mathrm{Ga}-$ doped $\mathrm{ZnO}$ (AZO or GZO) have attracted much attention. ${ }^{13-15}$ Although AZO thin films can achieve optical and electrical performances similar to those of ITO, their main drawback is the chemical and environmental stability, especially in the presence of high $\mathrm{T}$ and moisture. ${ }^{14,16-19}$ The degradation due to the adsorption of water vapour at the grain boundaries, which leads to a capture of free electrons, strengthens the contribution of the grain boundary scattering to the carrier transport and reduces the carrier concentration and mobility, preventing AZO films to be used in real applications that require long-term stability of the devices. Inverted PSCs using AZO films have always shown poor

\footnotetext{
${ }^{\text {a)} E l e c t r o n i c ~ m a i l: ~ n a d i a . f o r m i c a @ i c f o . e s ~}$

b)Electronic mail: dhriti.ghosh@icfo.es
}

performances when compared to standard cell structures incorporating ITO. ${ }^{20-22}$

In the present work, we demonstrate that an ultrathin $(5 \mathrm{~nm})$ oxidized $\mathrm{Ti}$ capping layer on $\mathrm{AZO}\left(\mathrm{AZO} / \mathrm{TiO}_{\mathrm{x}}\right)$ can improve the thermal, environmental stability and surface morphology of the underlying AZO, and that it can be employed to produce high-performance inverted polymer solar cells. AZO films were deposited on UV fused silica substrates by RF magnetron sputtering from a 98 wt. $\% \mathrm{ZnO}$ and $2 \mathrm{wt}$. \% $\mathrm{Al}$ target in a pure Ar atmosphere at $1.5 \mathrm{mTorr}$, $150 \mathrm{~W}$ RF power while maintaining the substrate at $200^{\circ} \mathrm{C}$. The $5 \mathrm{~nm}$ Ti layer was deposited at room temperature using RF magnetron sputtering (50 W RF power and 1.5 mTorr base pressure) from a target with a purity level of $99.99 \%$. Without breaking the vacuum, the subsequent oxidation of Ti was obtained by Oxygen plasma treatment in the same sputtering chamber at $8 \mathrm{mT}$ Torr and $40 \mathrm{~W}$ DC power for 15 min.

We fabricated inverted PSCs by blending Poly[[4,8bis[(2-ethylhexyl)oxy]benzo[1,2-b:4,5- $\mathrm{b}^{\prime}$ ]dithiophene-2,6-diyl] [3-fluoro-2-[(2-ethylhexyl)carbonyl]thieno[3,4-b]thiophenediyl]] (PTB7) (1-material, Canada) with $\mathrm{PC}_{71} \mathrm{BM}$ (ADS, USA) at a $1: 1.5$ ratio $\left(10 \mathrm{mg} \mathrm{ml}^{-1}\right.$ of polymer $)$ and dissolved in a mixed solvent system composed of chlorobenzene (CB) and 1,8-diiodooctane (DIO) (97:3 v/v\%). The used structure for the inverted solar cell was as follows: cathode $/ \mathrm{ZnO}$ $(40 \mathrm{~nm}) /$ active layer $(75 \mathrm{~nm}) / \mathrm{MoO}_{3} \quad(5 \mathrm{~nm}) / \mathrm{Ag} \quad(100 \mathrm{~nm})$ being the cathode ITO, $\mathrm{AZO}$, or $\mathrm{AZO} / \mathrm{TiO}_{\mathrm{x}}$. The $\mathrm{ZnO}$ layer and the PTB7:PC ${ }_{71} \mathrm{BM}$ blend were spin coated over the different cathodes using the same experimental conditions under controlled atmosphere in a globe box. The anode composed of $\mathrm{MoO}_{3} / \mathrm{Ag}$ was thermally evaporated through a mask $\left(0.096 \mathrm{~cm}^{2}\right)$ in an evaporator connected to the same globe box. The current-voltage (I-V) characteristics were obtained under a 1 sun AM 1.5G spectrum illumination from a solar simulator (Abet Technologies model Sun 3000).

We first optimized the deposition conditions of the AZO film to achieve the lowest electrical sheet resistance for a 


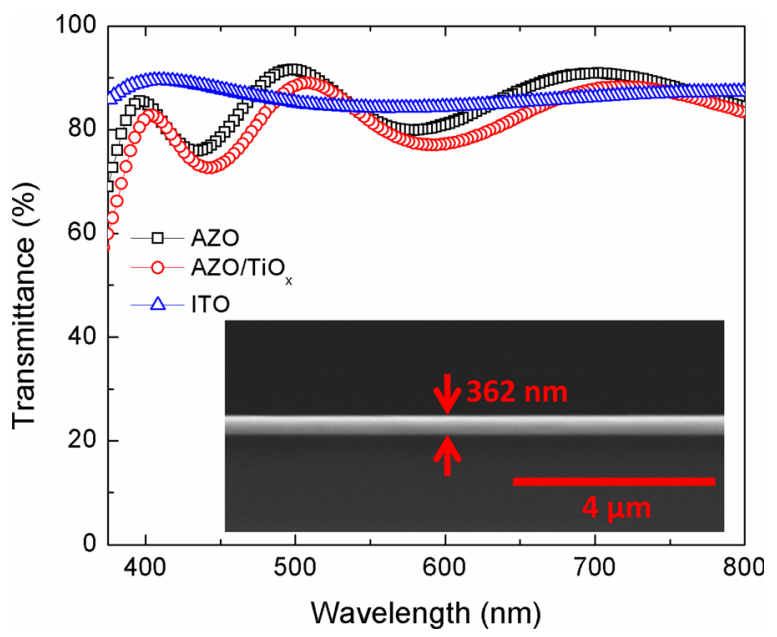

FIG. 1. Optical transmittance spectra of $\mathrm{AZO}, \mathrm{AZO} / \mathrm{TiO}_{\mathrm{x}}$, and ITO films in the visible range. The average transmission $\left(\mathrm{T}_{\mathrm{vis}}\right)$ values are $85 \%, 82 \%$, and $86 \%$, respectively. The inset is the cross section SEM image of the AZO film showing a thickness of $362 \mathrm{~nm}$. The sheet resistance of ITO is $21 \Omega / \mathrm{sq}$ while those of AZO and $\mathrm{AZO} / \mathrm{TiO}_{\mathrm{x}}$ are both $20 \Omega /$ sq.

given optical transmittance. Fig. 1 shows the optical transmittance spectra in the $300-800 \mathrm{~nm}$ wavelength range of $\mathrm{AZO}$ and $\mathrm{AZO} / \mathrm{TiO}_{\mathrm{x}}$ films compared with a commercial ITO-coated glass substrate, which has an average visible optical transmittance $\left(\mathrm{T}_{\mathrm{vis}}\right)$ of about $86 \%$ and an electrical sheet resistance $\left(\mathrm{R}_{\mathrm{s}}\right)$ of $21 \Omega / \mathrm{sq}$. AZO and $\mathrm{AZO} / \mathrm{TiO}$ x films have a $\mathrm{T}_{\mathrm{vis}}$ of $85 \%$ and $82 \%$, respectively, and both $\mathrm{R}_{\mathrm{s}}$ of about
$20 \Omega /$ sq. Note that capping AZO with an oxidized Ti layer does not change significantly the $\mathrm{R}_{\mathrm{s}}$ of the electrode. The transmittance in the near-infrared region is reduced due to the absorption of free carriers, and the Fabry-Perot oscillations fringes result from random thickness variations. The Scanning Electron Microscopy (SEM) cross section micrograph included as inset in Fig. 1 shows a $362 \mathrm{~nm}$ thick AZO film deposited on the silica substrate.

There are already some reports on the combination of ultrathin metals and TCOs as Transparent Electrodes (TEs). Recently, Bernede et al. deposited a very thin metal layer $(0.5-1.5 \mathrm{~nm})$, preferably $0.5 \mathrm{~nm}$, on the top of TCOs to improve their functionality. ${ }^{21}$ It was found that the insertion of an ultra thin metal films between the TCO anode and the organic layer improves the solar cell performance because of a greater carrier injection and better energy levels matching. On one hand, capping the TCO with such thin metal layers, which tend to have a discrete island-like morphology, results in an incomplete protection of the underlying AZO against the environment or detrimental interaction with other layers forming the device. On the other hand a thick metal layer reduces significantly the optical transmission. Therefore, there exists an optimum thickness of the metal capping layer corresponding to which the layer morphology changes from an island distribution to a continuous layer (percolation threshold). Previous work ${ }^{23}$ has demonstrated that the percolation thickness of titanium is in the range $2.7 \mathrm{~nm}-3.1 \mathrm{~nm}$ $( \pm 0.1 \mathrm{~nm})$. We opted to use $5 \mathrm{~nm}$ thick sputtered Ti layer
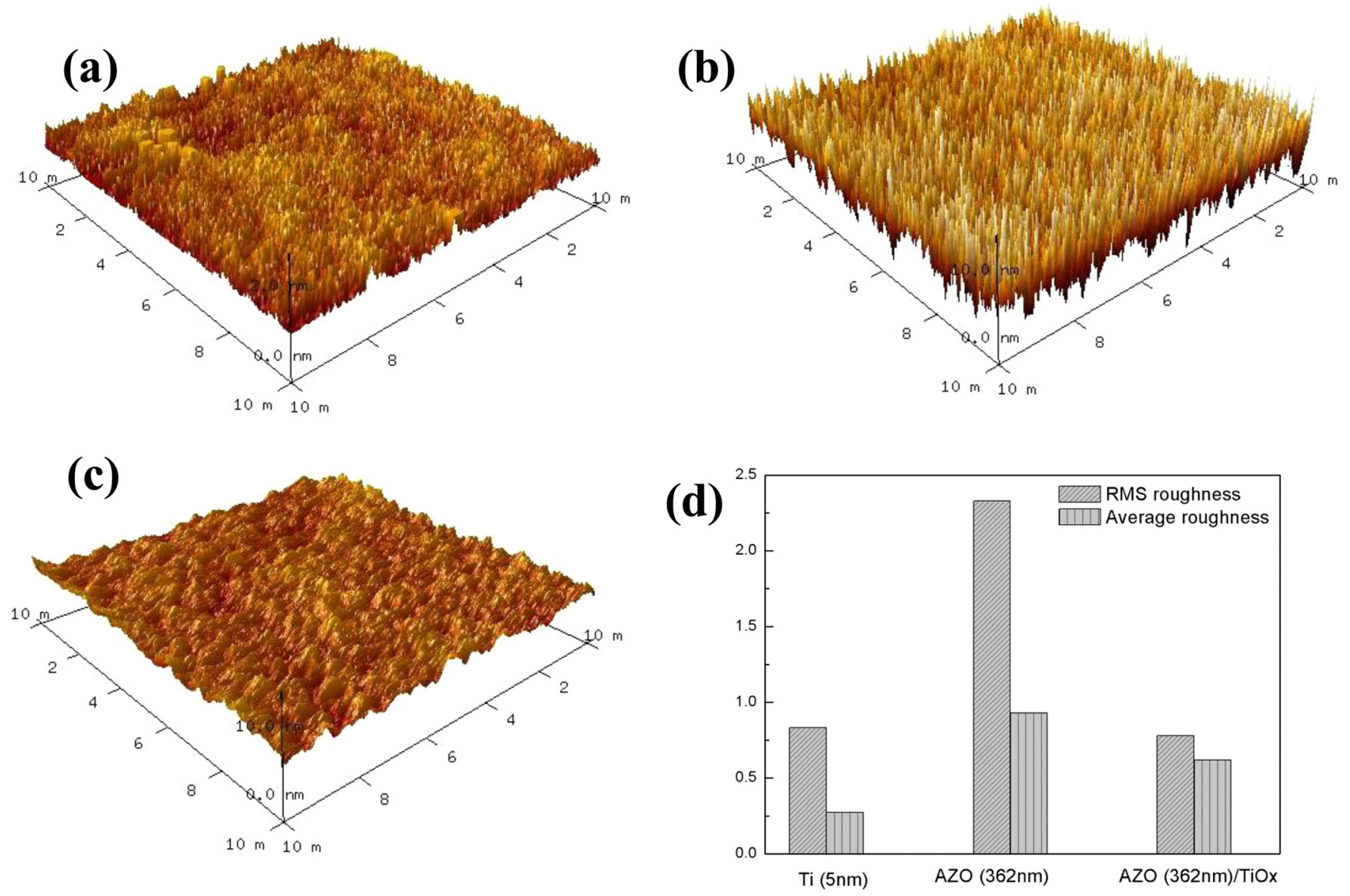

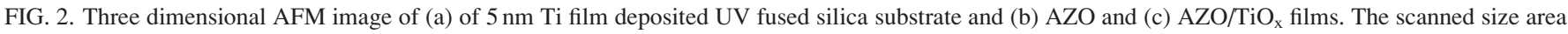
is $10 \mu \mathrm{m} \times 10 \mu \mathrm{m}$. (d) Histogram showing the RMS and average roughness of all the deposited films. 

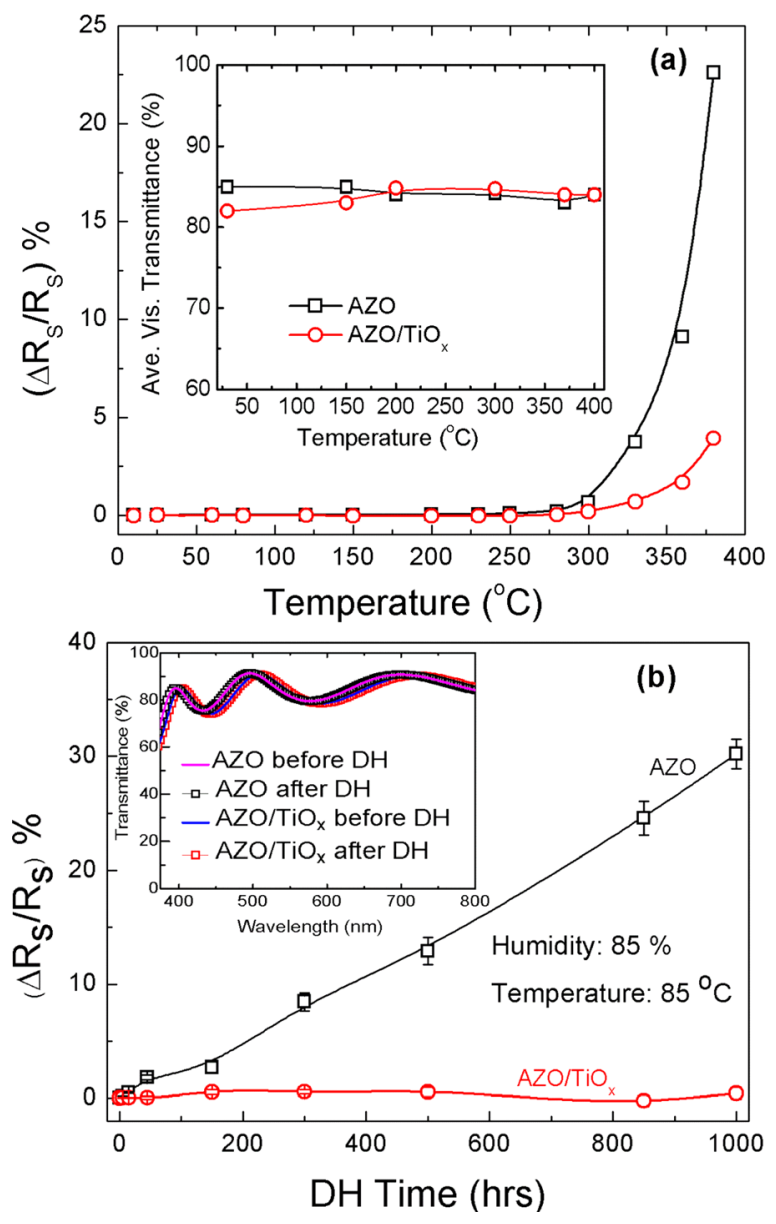

FIG. 3. (a) Electrical sheet reistance as a function of temperature for AZO films without and with $5 \mathrm{~nm}$ oxidized Ti capping layer. The inset is the average visible transmittance as a function of temperature. (b) Electrical sheet resistance as a function of time for damp heat test performed at $85^{\circ} \mathrm{C}$ and $85 \%$ relative humidity. The inset shows the optical transmittion of the samples before and after DH test.

which is continuous, covering completely the AZO surface, thus ensuring chemical and environmental stability. Since this thickness reduces the transmittance of AZO by about $20 \%$, an in situ oxygen plasma treatment was carried out to produce an antireflective oxide $\left(\mathrm{TiO}_{\mathrm{x}}\right)$ on the top of the $\mathrm{Ti}$ layer. In such a way the optical transmission is almost fully recovered and brought back to the AZO values.

The surface topography of the $5 \mathrm{~nm}$ Ti sputtered directly on the glass substrate (Fig. 2(a)) reveals a uniform and continuous smooth film with a Root Mean Square (RMS) roughness of $0.67 \mathrm{~nm}$ (Fig. 2(d)). When deposited on the AZO layer the Ti had the very important effect to smoothen its surface (Figs. 2(b) and 2(c)), reducing the roughness of a factor of 3, from $2.33 \mathrm{~nm}$ (AZO only) to $0.78 \mathrm{~nm}$ (AZO with oxidized Ti) RMS values (Fig. 2(d)). Such smoothening effect increases the quality of subsequent layers grown on the TE and reduces fringe fields, preventing leakage current and formation of morphological defects. ${ }^{24}$

It is well known that Ti oxide (titania) has a substantial oxygen/water protection and scavenging effect originating from the combination of photocatalysis and inherent oxygen deficiency. ${ }^{25}$ To explore these effects, AZO films with and without a $\mathrm{TiO}_{\mathrm{x}}$ layer were made and underwent subsequent thermal treatments, each 45 min long, in ambient atmosphere in the $30^{\circ} \mathrm{C}-400^{\circ} \mathrm{C}$ temperature range. By capping the $\mathrm{AZO}$ film with the oxidized $\mathrm{Ti}$ layer, the resulting structure becomes more stable. It can be seen in Fig. 3(a) that the electrical properties of both samples remain practically unchanged as temperature varies from $30^{\circ} \mathrm{C}$ to $300^{\circ} \mathrm{C}$. However, when temperature increases from $300^{\circ} \mathrm{C}$ to $400^{\circ} \mathrm{C}$, the $\mathrm{R}_{\mathrm{s}}$ of the AZO sample increases whereas the change is negligible for the AZO capped with oxidised Ti sample. This indicates that the $\mathrm{TiO}_{\mathrm{x}}$ capping prevents effectively the oxidation of the AZO film at high temperature and improves its properties. In addition, $\mathrm{T}_{\text {vis }}$ of AZO decreases while that of capped AZO increases during the thermal annealing process, most likely due to further oxidation and associated increase of antireflection effect (inset Fig. 3(a)). Damp Heat (DH) tests were carried out for more than one month at $85{ }^{\circ} \mathrm{C}$ and $85 \%$ relative humidity to demonstrate the better stability of the $\mathrm{AZO} / \mathrm{TiO}_{\mathrm{x}}$ based electrode compared to AZO. It was found that the oxidized ultrathin Ti greatly stabilizes the electrical as well as optical properties of AZO, also under these dramatic conditions. As it is shown in Fig. 3(b), a large increase in $R_{\mathrm{s}}$ after $500 \mathrm{~h}$ was observed for $\mathrm{AZO}$ while for $\mathrm{AZO} / \mathrm{TiO}_{\mathrm{x}}$ the degradation remains negligible up to $1000 \mathrm{~h}$. The DH treatment had no strong effect even on the optical properties of these films. The morphological degradation of AZO is likely to be intimately correlated with hydrolysis-induced corrosion processes that may have occurred at the grain boundaries. However, the use of the $\mathrm{TiO}_{\mathrm{x}}$ interlayer reduces the sensitivity to oxygen and water vapor and hinders their intrusion into the active polymers.

Finally, as a proof of concept, inverted PSCs were fabricated over the more commonly used ITO electrode and both AZO electrodes developed in this study. PTB7 photovoltaic

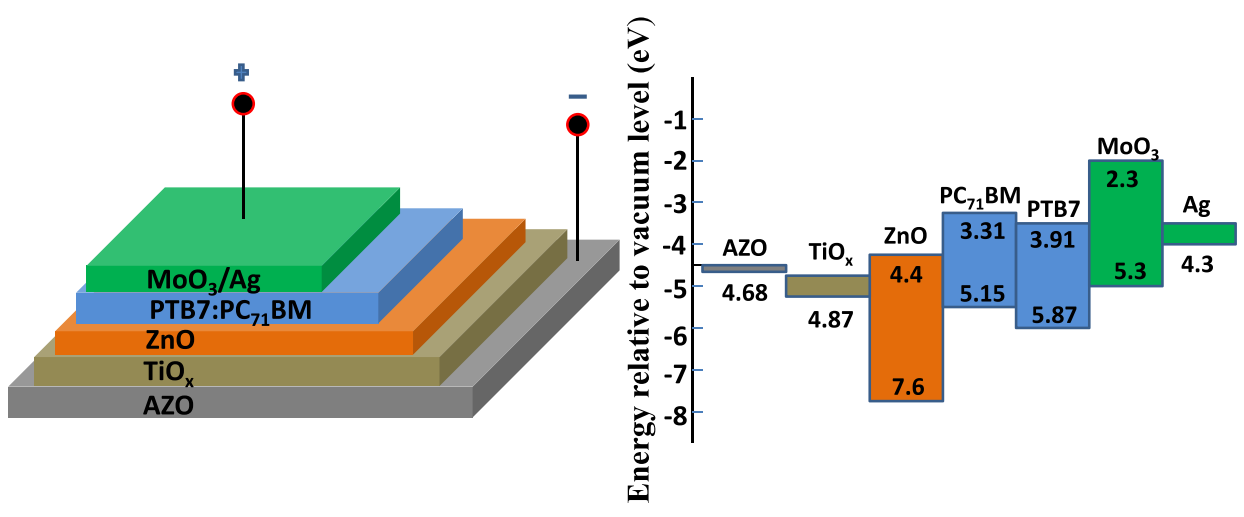

FIG. 4. (left) Device configuration and (right) the energy band diagram of the inverted polymer solar cell. 

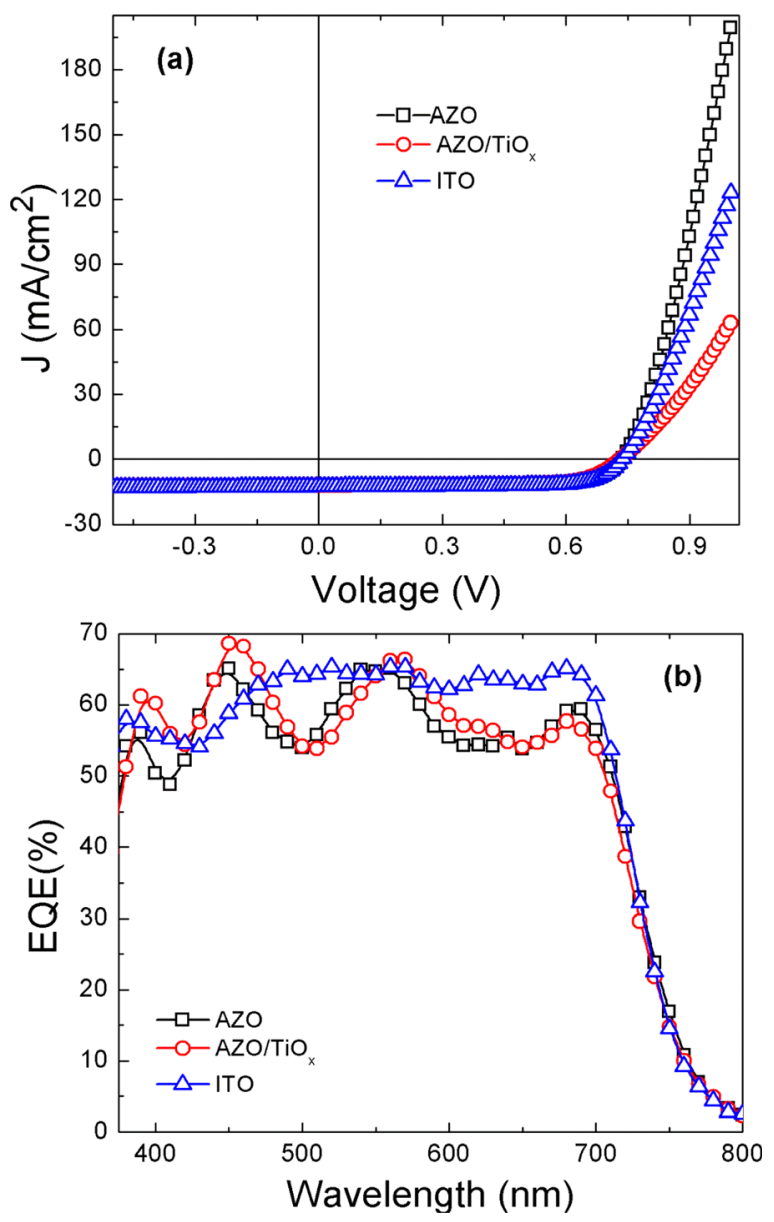

FIG. 5. (a) J-V curves of the inverted PTB7:PC71BM solar cells with AZO and $\mathrm{AZO} / \mathrm{TiO}_{\mathrm{x}}$ layers under a 1 sun $\mathrm{AM} 1.5 \mathrm{G}$ spectrum illumination (b) corresponding EQE spectra. The ITO-based device curves are shown for comparison.

polymer was chosen as it is one of the best performance polymers reported to date. The architecture of the fabricated $\mathrm{AZO} / \mathrm{TiO}_{\mathrm{x}}$ device is shown in Fig. 4(left) together with the corresponding energy level diagram ${ }^{26,27}$ (right). The approximate work functions of $\mathrm{AZO}$ and $\mathrm{AZO} / \mathrm{TiO}_{\mathrm{x}}$ films, measured experimentally by a Kelvin Probe Force Microscopy, were $4.68 \mathrm{eV}$ and $4.87 \mathrm{eV}$, respectively. The current density-voltage $(J-V)$ curves of the fabricated devices are showed in Fig. 5(a). Table I summarizes the short circuit current $\left(\mathrm{J}_{\mathrm{sc}}\right)$, open circuit voltage $\left(\mathrm{V}_{\mathrm{oc}}\right)$, fill factor $(\mathrm{FF})$, and power conversion efficiency (PCE) of the best devices using ITO, AZO, and $\mathrm{AZO} / \mathrm{TiO}_{\mathrm{x}}$ as cathodes. When the solar cell device was fabricated on glass/AZO substrates we achieved a PCE of $6.6 \%$ with a $\mathrm{J}_{\mathrm{sc}}$ of $12.0 \mathrm{~mA} \mathrm{~cm} \mathrm{~cm}^{-2}$, a $\mathrm{V}_{\text {oc }}$ of $0.737 \mathrm{~V}$, and a FF of 0.75 . When the solar cell device was fabricated on glass/AZO/TiO ${ }_{x}$ substrates we achieved a PCE of $6.3 \%$
TABLE I. Device performance of the inverted organic solar cell with different transparent cathodes.

\begin{tabular}{lcccc}
\hline \hline Electrode & $\mathrm{J}_{\mathrm{sc}}\left(\mathrm{mA} / \mathrm{cm}^{2}\right)$ & $\mathrm{V}_{\mathrm{oc}}(\mathrm{V})$ & $\mathrm{FF}$ & PCE $(\%)$ \\
\hline $\mathrm{AZO}$ & 12.0 & 0.737 & 0.75 & 6.6 \\
$\mathrm{AZO} / \mathrm{TiO}_{\mathrm{x}}$ & 12.1 & 0.732 & 0.72 & 6.3 \\
$\mathrm{ITO}$ & 12.7 & 0.737 & 0.74 & 7.0 \\
\hline \hline
\end{tabular}

with a $\mathrm{J}_{\mathrm{sc}}$ of $12.1 \mathrm{~mA} \mathrm{~cm}{ }^{-2}$, a $\mathrm{V}_{\mathrm{oc}}$ of $0.732 \mathrm{~V}$, and a $\mathrm{FF}$ of 0.72. Meanwhile, for the solar cell device fabricated on glass/ITO commercial substrates the $\mathrm{J}_{\mathrm{sc}}, \mathrm{V}_{\mathrm{oc}}$, and FF obtained were $12.7 \mathrm{~mA} \mathrm{~cm}^{-2}, 0.737 \mathrm{~V}$, and 0.74 , respectively, which resulted in a PCE of $7 \%$.

The cells on bare ITO and AZO-based substrates show very similar photovoltaic behaviour. When a thin Ti oxidized layer is deposited on AZO surface the Voc of the inverted solar cell is reduced by less than a $1 \%$. The energy level difference between the HOMO level of $\mathrm{ZnO}$ and the work function of $\mathrm{TiO}_{\mathrm{x}}$ can explain this slightly reduction of $\mathrm{Voc}$ according to the metal-insulator-metal model. ${ }^{28}$ Also a slightly difference in the value of the $\mathrm{FF}$ of the $\mathrm{AZO} / \mathrm{TiO}_{\mathrm{x}}$ electrode is observed regarded to the AZO or ITO electrodes. However, noticeably, the FF values obtained for the different transparent-electrode devices are over $70 \%$ which is indicative of low series resistances in the devices.

The efficiency losses of the AZO-based devices in comparison with the ITO reference device is mainly due to a $5.5 \%$ decrease in the short circuit current for the AZO device and a $4.7 \%$ decrease in the short circuit current for the $\mathrm{AZO} / \mathrm{TiO}_{\mathrm{x}}$ device. The difference in $\mathrm{J}_{\mathrm{sc}}$ between the reference device and AZO-based cells can be clearly seen in the External Quantum Efficiency (EQE) curves, shown in Fig. 5(b) where a different distribution of energy absorption can be observed. With respect to the ITO reference, the slightly lower transmittance together with the Fabry-Perot oscillations presented by the AZO-based devices (Fig. 1) resulted in less energy absorption at $500 \mathrm{~nm}$ and between $600 \mathrm{~nm}$ and $700 \mathrm{~nm}$ where the active material absorbs light. Noticeably, the situation is favourable for the AZO-based devices at around $400 \mathrm{~nm}$ and $450 \mathrm{~nm}$ where the energy absorption is larger than that of the ITO reference device, which partially compensates the current loss at larger wavelengths. The obtained values of Rs, $T_{v i s}$, and PCE reported in Table II compare favourably to the state-of-the-art where AZO films are used as TEs for PSCs. In fact, our work has achieved the highest PCE using AZO based TE reported so far.

In conclusion, we demonstrated that an ultrathin $(\sim 5 \mathrm{~nm})$ oxidized Ti film can considerably improve the stability in ambient atmosphere and harsh environmental

TABLE II. Comparison between our work and previous ones where AZO based electrodes are used for organic solar cells.

\begin{tabular}{lccll}
\hline \hline Reference & $\mathrm{R}_{\mathrm{s}}(\Omega / \mathrm{sq})$ & $\mathrm{T}_{\mathrm{vis}}(\%)$ & \multicolumn{1}{c}{ Solar cell architecture } \\
\hline 21 & 10 & 85 & $\mathrm{AZO} / \mathrm{Au} / \mathrm{CuPc}: \mathrm{C}_{60} / \mathrm{Alq} / \mathrm{Al}$ & $\mathrm{PCE}(\%)$ \\
13 & 26 & 86 & $\mathrm{AZO} / \mathrm{CuPc}: \mathrm{C}_{60} / \mathrm{TPBI} / \mathrm{Al}$ & 1.40 \\
29 & 4.59 & 85 & $\mathrm{AZO} / \mathrm{PEDOT}: \mathrm{PSS} / \mathrm{P} 3 \mathrm{HT}: \mathrm{PCBM} / \mathrm{Ca} / \mathrm{Al}$ & 1.3 \\
22 & 20 & 85 & $\mathrm{AZO} / \mathrm{P} 3 \mathrm{HT}: \mathrm{PCBM} / \mathrm{MoO}_{3} / \mathrm{Ag}$ & 2.01 \\
Our work & 20 & 82 & $\mathrm{AZO} / \mathrm{TiO}_{\mathrm{x}} / \mathrm{ZnO} / \mathrm{PC}_{71} \mathrm{BM}: \mathrm{PTB} 7 / \mathrm{MoO} /_{3} / \mathrm{Ag}$ & 3.06 \\
\hline \hline
\end{tabular}


conditions of the underlying AZO as well as its surface morphology. The proposed $\mathrm{AZO} / \mathrm{TiO}_{\mathrm{x}}$ electrode worked effectively as a transparent cathode for polymer solar cells, showing record conversion efficiencies close to those of ITO. The work demonstrates that the proposed TE is a serious competitor to overcome the high cost of ITO.

We acknowledge the Ministerio de Economía y Competitividad which supported the work under Grant Nos. MAT2011-28665, IPT-120000-2010-29, IPT-2012-0986120000, and CSD2007-00046.

This work was also supported by Obra Social "La Caixa" and by the Ministerio de Ciencia e Innocavio trough Grant No. TEC 2010-14832.

${ }^{1}$ F. C. Krebs, Sol. Energy Mater. Sol. Cells 93, 465 (2009).

${ }^{2}$ J. Y. Kym, K. Lee, N. E. Coates, D. Moses, T.-Q. Nguyen, M. Dante, and A. J. Heeger, Science 317, 222 (2007).

${ }^{3}$ W. U. Huynh, J. J. Dittmer, and A. P. Alivisatos, Science 295, 2425 (2002).

${ }^{4}$ N. Espinosa, R. Garcia-Avlverde, A. Urbina, F. Lenzmann, M. Maceau, D. Angmo, and F. C. Krebs, Sol. Energy Mater. Sol. Cells 97, 3 (2012).

${ }^{5}$ H. Y. Chen, J. H. Hou, S. Q. Zhang, Y. Y. Liang, G. W. Yang, Y. Yang, L. P. Yu, Y. Wu, and G. Li, Nat. Photonics 3, 649 (2009).

${ }^{6}$ A. Martinez-Otero, X. Elias, R. Betancur, and J. Martorell, Adv. Opt. Mater. 1, 37 (2013).

${ }^{7}$ Y. Liang, Z. Xu, J. Xia, S. Tsai, Y. Wu, G. Li, C. Ray, and L. Yu, Adv. Mater. 22, E135 (2010).

${ }^{8}$ S. Kirchmeyer and K. J. Reuter, Mater. Chem. 15, 2077 (2005).

${ }^{9}$ M. Zhang, S. Fang, A. A. Zakhidov, S. B. Lee, A. E. Aliev, C. D. Williams, K. R. Atkinson, and R. H. Baughmasn, Science 309, 1215 (2005).

${ }^{10}$ K. S. Kim, Y. Zhao, H. Jang, S. Y. Lee, J. M. Kim, K. S. Kim, J. H. Ahn, P. Kim, J. H. Choi, and B. H. Hong, Nature 457, 706 (2009).
${ }^{11}$ F. Bonaccorso, Z. Sun, T. Hasan, and A. C. Ferrari, Nature Photon. 4, 611 (2010).

${ }^{12}$ E. C. Garnett, W. Cai, J. J. Cha, F. Mahmood, S. T. Connor, M. G. Christoforo, Y. Cui, M. D. McGehee, and M. L. Brongersma, Nature Mater. 11, 241 (2012).

${ }^{13}$ G. Murdoch, S. Hinds, E. Sargent, S. Tsang, L. Mordoukhovski, and Z. Lu, Appl. Phys. Lett. 94, 213301 (2009).

${ }^{14}$ T. Miyata, Y. Ohtani, T. Kuboi, and T. Minami, Thin Solid Films 516, 1354 (2008).

${ }^{15}$ I. S. Kim, S. H. Jeong, S. S. Kim, and B. T. Lee, Semicond. Sci. Technol. 19, L29 (2004)).

${ }^{16}$ J. Owen, M. S. Son, K. H. Yoo, B. D. Ahn, and S. Y. Lee, Appl. Phys. Lett. 90, 033512 (2007).

${ }^{17}$ W. Lin, R. Ma, J. Xue, and B. Kang, Sol. Energy Mater. Sol. Cells 91, 1902 (2007).

${ }^{18}$ T. L. Chen, R. Betancur, D. S. Ghosh, J. Martorell, and V. Pruneri, Appl. Phys. Lett. 100, 013310 (2012).

${ }^{19}$ T. L. Chen, D. S. Ghosh, N. Formica, and V. Pruneri, Nanotechnology 23, 395603 (2012).

${ }^{20}$ S. Cho, Y. T. Kim, W. H. Shim, S. Y. Park, K. D. Kim, H. O. Seo, N. K. Dey, J. H. Lim, Y. S. Jeong, K. H. Lee, Y. D. Kim, and D. C. Lim, Appl. Phys. Lett. 98, 023102 (2011).

${ }^{21}$ J. C. Bernède, Y. Berredjem, L. Cattin, and M. Morsli, Appl. Phys. Lett. 92, 083304 (2008).

${ }^{22}$ A. De Sio, K. Chakanga, O. Sergeev, K. von Maydell, J. Parisi, and E. von Hauff, Sol. Energy Mater. Sol. Cells 98, 52 (2012).

${ }^{23}$ T. W. H. Oates, D. R. McKenzie, and M. M. M. Bilek, Phys. Rev. B 70, 195406 (2004).

${ }^{24}$ G. Liu, J. B. Kerr, and S. Johnson, Synth. Met. 144, 1 (2004).

${ }^{25}$ A. Fujishima and K. Honda, Nature 238, 37 (1972).

${ }^{26}$ Z. He, C. Zhong, S. Su, M. Xu, H. Wu, and Y. Cao, Nat. Photonics 6, 591 (2012).

${ }^{27}$ A. K. K. Kyaw, X. W. Sun, C. Y. Jiang, G. Q. Lo, D. W. Zhao, and D. L. Kwong, Appl. Phys. Lett. 93, 221107 (2008).

${ }^{28}$ I. D. Parker, J. Appl. Phys. 75, 1656 (1994).

${ }^{29}$ J. Park, K. J. Park, K. -II Park, S -I. Na, and H. K. Kim, J. Phys. D: Appl. Phys. 43, 115101 (2010). 